\title{
Standardization of the Sites of Tourist Destinations in Ukraine as a Means of Implementation of the Internet Technologies on the Local Territorial Level of the Tourist Area
}

\author{
Zhurayeva Karina Alizhonivna ${ }^{1}$ \\ ${ }^{1}$ Taras Shevchenko Kiev National University, Kiev, Ukraine \\ Correspondence: Zhurayeva Karina Alizhonivna, Kiev, Ukraine, Mechnikova 22 a, 3, Ukraine. Tel: \\ 38-067-238-3151. E-mail: zhurayeva@gmail.com
}

Received: April 29, 2014 Accepted: July 23, 2014 Online Published: July 29, 2014

doi:10.5539/ass.v10n15p273 URL: http://dx.doi.org/10.5539/ass.v10n15p273

\begin{abstract}
In this article the single approach to standardization of the sites of the touristic destinations in Ukraine was offered as a means of implementation of the Internet-technologies on the local territorial level of the touristic area.

It was proved that the rapid development of the innovation technologies led to the necessity to bring the touristic sites in compliance with the world standards (requirements). It should be implemented on the level of standardization of structure of the touristic sites. Such situation will lead to increase of the competitive ability of the touristic branch of Ukraine on the international market and distribution of the information about Ukraine in the global scales.

The author forms the single approach to application of the certain group of technologies on the level of all destinations, which form the spatial framework of the innovative system of the touristic site in Ukraine.

The implementation of the offered standardized structure allows touristic destination of Ukraine providing touristic product with assistance of the innovative technologies and enhances its competitive ability in the area of tourism. The integration to the systems of reservation of the basic services and social networks Facebook, and Twitter will promote to enhancement of the quantity of the foreign tourists in Ukraine.
\end{abstract}

Keywords: travel websites, Internet technologies in tourism, tourism in Ukraine, innovative technologies in tourism, travel destination.

\section{Introduction}

In the rapid conditions of innovative technologies and their application in the areas of tourism, structure standardization of sites of tourist destinations and Site Development becomes important for Ukraine and corresponds to the global requirements.

The issues of promotion of the touristic services through the world network of Internet, implementation of the Internet-technologies in tourism, connection of the electronic commerce and Internet-resources of the tourism industry, virtualization of the touristic market, marketing in tourism, automated monitoring of the sites in the area of business tourism were considered by the scientists of the different countries. We should separate the following works on the tourism marketing - the Electronic "Word of Mouth Radio" (Altunin, 2014), The Usage of the Internet-technologies in the Tourism Marketing (Umavova, 2012), The Internet-opportunities of Promotion of the touristic services (Lemeshko, 2013).

The electronic commerce and Internet-technologies in the tourism are studied in the works The Influence of the Electronic Commerce and Internet-resources on the Development of the Tourism Industry (Kudasheva, 2012) and The Internet-technologies and Commerce in Tourism: Tendencies and Prognoses (Semenovich, 2007).

Also Internet can be a means of formation of consumption culture in tourism. The works The Usage of the Instruments of Internet-monitoring for Activation of the Process of Development of the Entrance Tourism in RF (Maksimova, 2011) and Internet as a Means of Formation of Consumption Culture in the Touristic Industry: Generation Aspect (Malysheva, 2013) are devoted to this. 
The separate group of study belongs to the influence and evaluation of the information technologies for the tourism development: Internet-technologies in the Amateur Tourism (Gelman, 2013), The Virtual Tourism as the Contemporary Form of Activity on the Touristic Market (Kuznetsov, 2014), The Influence of the Information Technologies on the Development of the International Tourism (Pogorelov, 2014), The Evaluation of the Contemporary Tendencies of Promotion of the Touristic Product (Serdyukova, 2012), The Internet-intelligence and Automated Monitoring of the Sites in the Area of Business Tourism of RF (Suvorova, 2012).

The study of this question was conducted in a large number of works of the scholars both theoreticians and practitioners. Among them - S. Melnichenko (2007), M. Skopen (2005), P. Keller (2005) and others. Having analyzed their works and websites of tourist destinations in Ukraine, the author offered a unified approach to the standardization of websites that would represent Ukraine at the international level and meet the global requirements.

The aim of this article is the standardization of sites of tourist destinations in Ukraine as a means of implementation of the Internet technologies on the local territorial level of the tourist area. This will enhance the competitiveness of the site and the dissemination of information about Ukraine and its destination at the international market.

\section{The Main Material}

The actual task of optimization of the territorial structure of the tourism industry in the country must be the formation of a unified approach to the usage of a specific group technologies at all levels of destinations with forming spatial framework of the innovation system. First of all, we speak about Internet technologies, and the first step in this direction is offered that provides structure standardization of websites of tourist destinations and development of sites that meet these requirements, and their search engine optimization.

The unified concept of Internet sites of tourist destinations in Ukraine, providing the appropriate site specific requirements, mandatory presence of the certain tools and a sequence of actions must be formed.

Thus, the process of searching information for planning the tourist travel with assistance of the Internet usually involves three stages. The first one of them is the search, or conduction by means of the search engines (i.e, Excite, Google, Yahoo!, etc.) used to select the useful sources of information, or output directly to the website, if the consumer knows these sites in advance. In order to direct the efforts of a potential visitor in the desired direction, it is necessary by any means to search the queries, moreover, site to schedule representation in all possible search engines. The sites found by the consumer help to evaluate the positions in accordance with a number of the criteria, which must be considered when creating it.

First of all, we speak about the effect of "the first impressions", expressed in an instant assessment of the usefulness and relevance of information, forcing the user to search further or stay on the site results. Other criteria for modern researchers attribute to the quality of information, ease of use, reliability, level of involvement of the consumer into the selection process of the tourism products, and to the links between the site and the user.

R. Turovskyi states that now it is worth if using the geographical approach, particularly the methodology of district zoning and geographical modelling for researches of the innovative activity that allows conduction of the system research of horizontal and vertical structure of the phenomena, study of their heterogeneity and territorial hierarchy (Turlapov, 2007).

Innovative technologies can be considered not only as the object of geographical researches, but as a component of its instruments. In the scientific periodicals the special term "geoinnovatics" appeared that finally evidences about the necessity to meet the modern level of science and social development (Golubchenko, 2012). Thus, in the works of I.A. Portnyanskyi, I. Golubchenko and K. Shevchuk the directions of modifications of the traditional methods of researching the regional geography are outlined and the modern and perspective technologies of researches are defined. The generalization of ideas of the mentioned authors, as well as the suggestion that the notion "method" is equal to the notion "technological process" allows separation of such tendencies as distribution of the innovative technologies in geographical researches (Golubchenko, 2012; Bezdudnyi, 1998; Portyanskii, 1989; Shvets, 2005):

1. Application of the empirical and theoretical researches of the modern instruments, i.e. corresponding software, Internet-technologies, mobile-technologies and etc., in the traditional methodology. First of all, it concerns to the descriptive (with the help of thematic databases), cartographical (with the help of special software) methods, observation method (with using computerized observance and software, that provides storage and processing of the data), district zoning, modelling, cosmic survey (with software for effective decoding of its results). The 
constant improvement and renewal of software that allows maximally enhance the exactness of researches can be considered as continuation of the tendency.

2. Formation and constant improvement of the special geographical information systems (GIS), expert systems and systems of monitoring, including social-economic one, which are understood as periodically repeated observations over one or many elements of social-economic environment in concrete geospatial-sentinel position data that is accomplished with certain aim under the advanced developed programme.

3. Diversification of the sources of geographical information and simplification of the access to it at the expense of Internet-technologies.

4. Wider involvement into geographical researches of the methodological apparatus of the other sciences as geochemistry, geophysics, sociology, political science, mathematics, and application of the completely specific methods of narrative, entropic, semantic and sociolinguistic analysis.

Thus, geography as a science has substantial potential of innovative and own modern instruments for full-fledged researches of the processes of branch and territorial diffusion of the innovative technologies and their influence on popularization of the space.

The study of innovations in the area of tourism undoubtedly has spatial character that is explained, first and foremost, by the spatial character of the very tourism.

Austrian researcher, professor M.-A. Hjalager offers own classification of innovations in tourism (Ferreira, 2014):

1. Regular innovations including involvement of the new investments, directed at enhancement of the labour productivity; teaching of the entrepreneurs and employees; additional enhancement of servicing quality and standards.

2. Revolutionary innovations, mainly - distribution of the new technologies at the enterprises; implementation of the new methods of work with the staff; search of the new methods of work with old markets.

3. Niche innovations: encouragement of the entrepreneurs to use the new possibilities for business; enter into the new market alliances; creation of the new combinations of the existing products.

4. Architectural innovations, to which the author includes creation of the new events and attractions, capable to change demand; implementation of the new organizational structures; establishment of the advanced experience centers, whose activity has orientation on the conduction of the branch researches and expansion of their results.

K. Kano singles out five basic criteria of classification of innovations in tourism - the space of usage, the degree of innovation, perceptibility for the enterprise or region, and technical signs (Ali, 2011).

The Spanish researcher understands space as internal and external environment of innovation distribution of the enterprise or region. Taking into account that in the process of touristic activity the aggregate of technological connection between subjects occurs in the enterprise or region, in particular between tourists and consumers of touristic services and manufacturers of the touristic products and their components; between separate structural subdivisions inside the enterprise; between services manufacturers; between suppliers and intermediaries (touristic agents); between enterprises and local authorities; between enterprises and civil organizations etc. being guided by this criteria, F. Galyu considers as appropriate the separation of innovative technologies within the framework of each such interaction (Figueiredo, 2010).

The author offers to use processing approach to the systematization of innovative technologies, i.e. to divide them dependently on the typical technological cycles of the market subjects.

Thus, the technological operations of the typical touristic operator include the research of demand at the touristic market of the concrete country or region; supply development; formation of the range of tours and services; promotion of the supply at the foreign and domestic markets; the search for partners; creation of marketing, including agent networks; financial operations; agreement of possible variants of supply with foreign initiative touristic operators; conclusion of agreements; ensuring of touristic servicing provision; ensuring of servicing obtainment; working with the clients and touristic agents. Much simpler operations are producing operations of the touristic agent, which include conduction of the demand research; the search of touristic operators and conclusions of agreements with them; adaptation of the touristic products to the local conditions; creation of the range of tours and services; advertisement and propaganda of their possibilities; contacts with local clients; ensuring of servicing provision; claim work with clients and touristic operators. Another participant of tourists' servicing - placement institution - has several essentially complex technological cycles (Golovko, 2012): reservation, guests' receipt, registration of documents, prepayment, provision of placement, night audit, 
organization of exit and calculation after exit; cleaning of residential and non-residential premises, running of linen economy, usage of the means for washing and cleaning, informative technologies, technologies of booking and reservation; control over technical and aesthetical state of the premises and technical condition of the equipment, mechanisms and automatic machinery. Technological cycles of destination, as the market subject are still a little-researched, but, in author's opinion, include conduction of marketing researches; planning and implementation of the marketing plans, including brand development, accumulation and distribution of information, organization and conduction of the advertisement and PR campaigns; realization of the measures on saving the resource tourism base; labelling and supporting the touristic routes in the proper condition; provision of certain standards of quality of the touristic product/services on their territory. Accordingly, each one of the mentioned technological cycles can be grounded on the usage of innovative technologies, as: automation of the process of reservation; documents circulation and work with clients, usage of the modern informative and communicative technologies in the advertisement activity, logistic approach to the route organization, and modern methods of staff motivation.

The European Tourism Council (ETC) jointly with the World touristic organization (UNWTO) offers to consider all technologies, which are used by the touristic enterprises and organizations in the Internet network, as the means of Internet-marketing (e-marketing) (Hjalager, 2002). The benefits of e-marketing are obvious, as with the help of its instruments there appears possibility to give quickly huge masses of information in the extremely convenient form to all target markets (saving the printing and eternal advertisement); to unite the representation of the touristic products and their sale; to provide feedback with consumers by means of the electronic mail, mobile connection, Internet-telephony, interactive interrogation etc.; quickly communication with partners and suppliers; organization PR-actions, connected with formation of the image of enterprises or the whole destinations, and their branding; to gather information and create databases with the aim of further usage in the marketing activity.

One of the most important e-technologies in tourism is the technology of creation and usage of so-called "content", i.e. information of the advertisement character, given to a consumer in the special format (television, voice, audio, HTLM, MP3, PDF, Word, Web, Flash, WML etc.) with the help of Internet carriers and individual mobile devices. These technologies are actual both at the level of separate destination, and enterprises of tourism area. Finally, they are brought to formation of the categories of information, necessary to a consumer or partner at the different stages of decision taking, creation of the marketing instruments (brand, positive news etc.), choice of the optimal format of data provision for the user, placement on the optimal carriers, and control over information renewal. Nowadays the modern tendency for choice of contents is active usage of software that ensures geographical identification of objects with assistance of geocoding or geographical information systems.

Beginning from 2005 the innovative technologies of information transfer by means of social networks (Facebook, Twitter, VKontakte, Odnoklassniki, Moj Mir etc.) and so-called informal communities ((User-generated content (UGC)), which include network diaries, subcastes, network platforms, Wiki-project became worldly used. Now, all they are widely used in the touristic marketing, as they give possibility to influence on the target audiences from different countries of the world through feedback, recommendations, advices, reports, and reclamations submitted by the other tourists. Thus, the atmosphere of non-bias, non-formality, and high trust is created. So, the subjects of touristic market predominantly have pages in social networks, where they place the most actual information, which quickly becomes accessible, and use those advertisement platforms for submission of certain appeals. The managers and workers of the touristic enterprises appeal to the potential consumers and through personal pages and foto/video reports, and ordinary travelers enhance interest to separate destinations, placing the stories about trips in detail. Moreover, there appear several completely touristic platforms in the Internet-space, which unite functions of booking system, forums and personal diaries of the tourists from all over the world. It is going about all-world projects Tripadvisor, Travel spots, Lonelypalnet, and the Russian projects Travel.ru, Vinskii Forum. Thus, the mentioned Internet-resources are the sample of usage of another innovative technology - mash up, or replenishment of web-resources, which unite data from several sources in one integrated instrument, for example, at unition of cartographic data of Google Maps with the data about means of location from Booking.com and about touristic attractions from the sites of local destinations, and it creates the new unique web-service, firstly not suggested by anyone of the mentioned sources.

One more innovative instrument of the touristic marketing in the Internet environment is so called wiki - the specialized web-sites, which structure and content the users can change on their own with assistance of instruments, provided directly at the site. In tourism we can separate the projects wikitravel.org and world66.com, in which space we can locate any information about touristic objects and destinations. 
The whole range of innovative technologies in tourism is connected with the notion of e-commerce - business activity that provided cooperation of the parties based upon information networks, i.e. by electronic means without direct physical contact, which basic forms can be called as sales of products/goods; advertisement and marketing measures; electronic payment with usage of the electronic payment systems; information exchange and establishment of the contacts between suppliers and customers; common conduction of business-processes, particular, organization of the virtual enterprises - specialists' groups and companies for conduction of joint commercial activity through network; distant learning, and consultations; conduction of tenders, competitions etc.; banking and financial services; execution of administrative and managerial functions (Hjalager, 2002). Now we can state that the tourism actively practice the sales of products as a direction through the sites of enterprises of location, transport companies, touristic operators and touristic agents, and through mediation of partners and specially created Internet-platforms. In the functional sense such platforms, using software, unite offer of many suppliers at the same time, allowing a consumer to compare and choose. Obviously, the oldest platforms for e-commerce in tourism are global distributions systems (GDS) Amadeus, Galileo, Worldspan, Sabre, which technologies are used by the touristic enterprises owing to connection of certain terminals. However, the modern stage of development of tourism pushes the market subjects to the search of new solutions - creation of the resources-wholesalers, which unite possibilities of several GDS simultaneously, and sometimes allow buying suppliers' services, not connected up to the global system, for example, budget aircraft companies, that was impossible 2 year ago.

It is necessary to state that the compulsory condition of existence of similar platforms is possibility to pay for services in the on-line regime, particularly, with the help of payment cars, payment systems or Internet-banking. The most popular systems now are Skyscanner, Momondo, Anywayanyday, Trirsta, Travel, and their Ukrainian version Tickets.ua.

According to the views of ETC and UNWTO experts the technologies of mobile commerce, particularly, mobile-marketing and other forms of individual digital assistance (Wi-Fi, 3G or 4G connection), MP3 technologies, particularly, usage of audio- and videoguides, individual and automobile electronic devices, equipped with technologies of access to the world network are combined with the technologies of GPS-navigation meet the demands of customerisation best of all. In relation to the mobile marketing, among its basic technologies the specialists name SMS and MMS deliveries, creation of the mobile versions of sites of destination and touristic enterprises, formation of mobile guides, usage of the satellite navigation systems, subcasting - creation of the sound and audio files in the radio style or television broadcasts (generally, virtual tours) and their loading into mobile devices through the Internet, provision of work of telephonic assistance centers. One of the groups of innovative technologies in the touristic business is connected with the modern tendency of convergence of mass media as a result of appearance of interactive digital television (iDTV). The technology allows a consumer restricting the information flows that go on its personal electronic devices by those ones, which represent interest for him. Particularly, for the ordinary tourist or guest of the hotel it means possibility to choose broadcast or film for viewing, and look the programmes of central, cable or satellite TV not by the schedule, but in a convenient time, play in the individual and network games, communicate with telephonic communicants of the subscriber with the help of television screen, define the themes of the news received in advance and receive speed access to the Internet network directly on the screen.

Moreover, trying to give a consumer as many opportunities as possible and provide attendance of the own site, the enterprises and organizations are inclined to diversify it due to the multimedia content - foreign currency calculators, interactive weather forecast, making of automobile, motorcycle, bicycle, pedestrian and touristic routes in the interactive regime, binding to such famous programmes as Google Maps and Google Earth, supply of the most actual news, computer games, measurement of carbonic acid, electronic delivery etc.

However, Internet-technologies are used not only with the aim of promotion of touristic product/service at the target market. The whole group of technologies relates to the category of those, which provide or encourage provision of the stable development of tourism on the concrete territory. In the majority of the scientific publications it is stated that these technologies include virtual tourism, creation of the geographic information systems (GIS), touristic information systems (TIS), touristic destination management systems (DMS), technologies of definition of the location for mobile devices (LBS), the global positioning systems, and technologies of intellectual transport system (ITC).

The factor of convenience, or as it is called in the literature, the factor of "the care information systems" (Keller P., 2005) means that the user needs without significant intellectual effort to navigate website, to understand its purpose and navigation system. Researchers believe that the convenience leads to the formation of positive intent of the consumer or user, and that it is ultimately the main purpose of any web-resource (Global Swot, 2014). 
The trust of a client as a factor of quality of the site destination, having formed owing to the reviews of famous people, presented the awards, known as links to web-resources, and a high level of security of payment transactions (Keller, 2005). One more factor is the quality - the extent of attraction of the user's choice that is provided by a variety of interactive visualization tools, and cartographic representations, and has a large number of selection parameters of the tourist product. All this allows the potential client to plunge into the atmosphere of destination, and increase his motivation.

Finally, the site must allow the user quick and easy obtainment of the necessary information in the individual mode, and displaying the feedback path.

The second stage of the user familiarity with the destination site (adequate assessment of the latter) is planning of travelling. This stage involves using of information not only in the pure form as the search capabilities, selection services, payment of their value directly on a Web page, rapid feedback to urgent questions.

The third stage occurs directly during the trip, when the consumer searches for more information about the specific services and resources, and identifies itself on the map destination.

Based on the experience of countries such as France, Germany, Italy, Norway and the United Kingdom, where for the convenience of visitors a unified approach has existed during many years in building websites of local tourist destinations, which positively contributes to the number of foreign tourists and more favourable spread of information at the international market.

The author offers to adopt the experience of our neighbours for a fruitful development of the tourist destinations of Ukraine at the international market and a substantial increase in the inflow of foreign tourists to our country. Based on the principles and methods of posting information on Internet sites and tourist destinations in the above-mentioned countries, the single standardized framework for websites of tourist destinations in Ukraine was offered.

So, based upon the foregoing considerations and using data of JBA Consulting Engineers conducted by a survey of tourists - the active Internet users, the author has developed a standardized structure and the most customer-friendly tourist destination site, which can be used as a basis for any destination in Ukraine (Fig. 1).

Table 1. Mandatory requirements for such web-resources

\begin{tabular}{|c|c|}
\hline № & Name \\
\hline 1 & $\begin{array}{l}\text { Creating a design using the elements specially designed for it as a brand, in particular, logo, slogan and } \\
\text { colour combination, public information, including through other media. }\end{array}$ \\
\hline 2 & Development of the most convenient destination for site navigation by the potential visitors. \\
\hline 3 & Simple and convenient content management system that allows you updating almost all sections of the site. \\
\hline 4 & Integration into social networks such as Facebook, Twitter and other social media channels. \\
\hline 5 & Possibility to be available in all types of mobile devices (mobile version). \\
\hline 6 & The presence of the visual slide-show on the main page and regularly updated photo content. \\
\hline 7 & $\begin{array}{l}\text { Opportunity of organization of several ways of access for users (registered, unregistered, members of } \\
\text { associations etc.) }\end{array}$ \\
\hline
\end{tabular}

8 Having a single approach to organizing information.

9 Reservation systems of integration for the basic services (air, bus, rail transport, accommodation, car rental, tickets to the event management), thematic sites, weather forecast, currency calculators, and interactive maps.

10 Presence of the special content for travelling - the search, routings, and announcements of events, etc.

11 Presence of the special sites for summary of business projects, industry associations, sponsors (banners, ads, etc.) and the opportunity of optimizing partner sites.

12 Multilingualism - duplication of the main pages in two compulsory languages - Ukrainian and English ones, as well as the languages of the target segments of destination.

13 Binding to one of the existing Internet banking systems that means giving the customer the opportunity to pay for the certain goods and services directly on the site. 

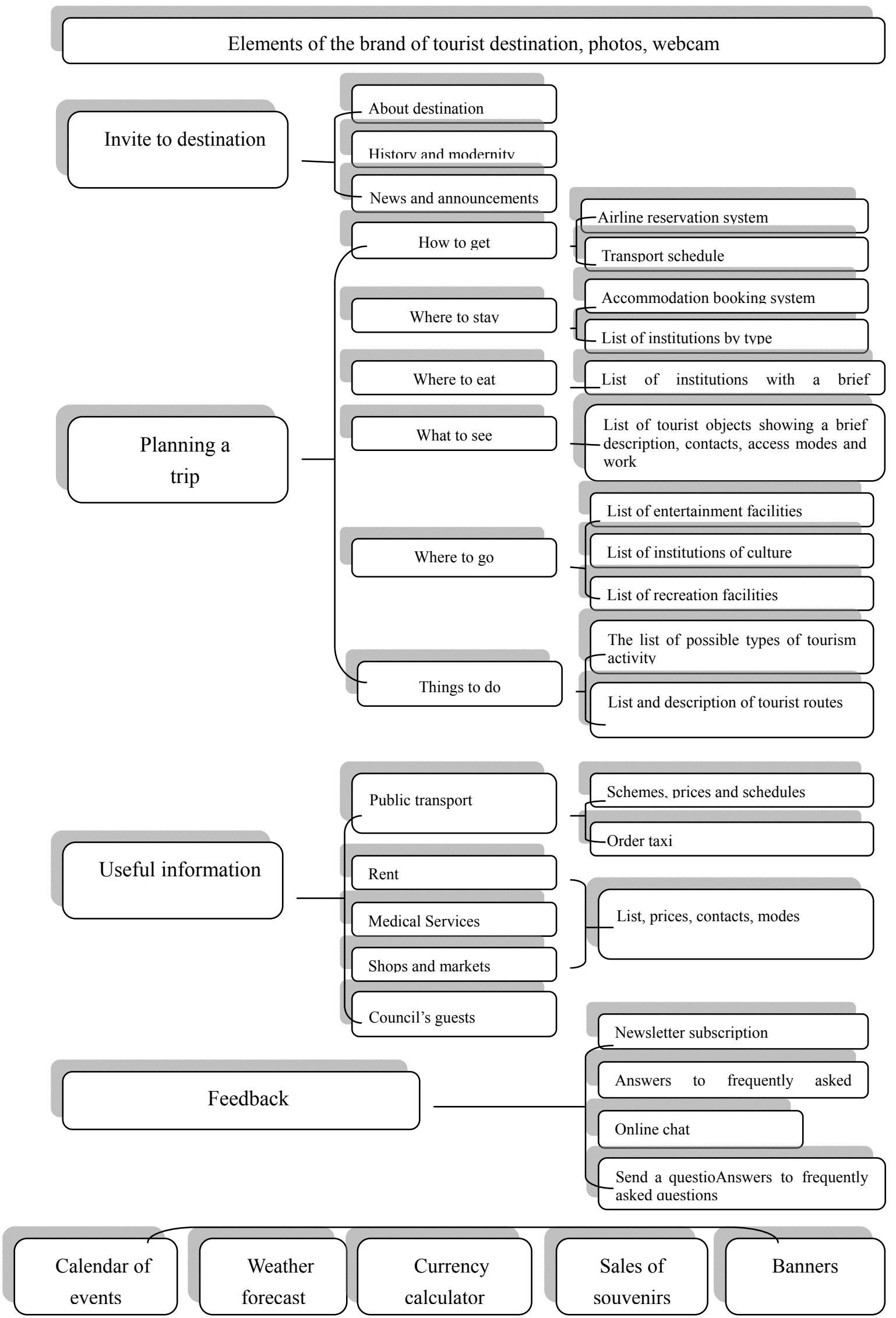

Figure 1. Standardized site structure of tourist destination 
Accordingly, the authors also offer mandatory requirements for such web-resources (table 1).

All of these activities in the development of websites of tourist destinations of Ukraine in accordance with a unified standard will contribute to raising Ukraine for a step higher in the world arena of the international tourism.

Any researches of the innovation processes in the tourism, except for the traditional mirco-, meso- and marcolevels must cover the level of destination as a production of the absolutely unique touristic product. Taking into account all above-mentioned, the offered methods of the studies of the innovation technologies in the tourism has the view, represented at Fig. 2.

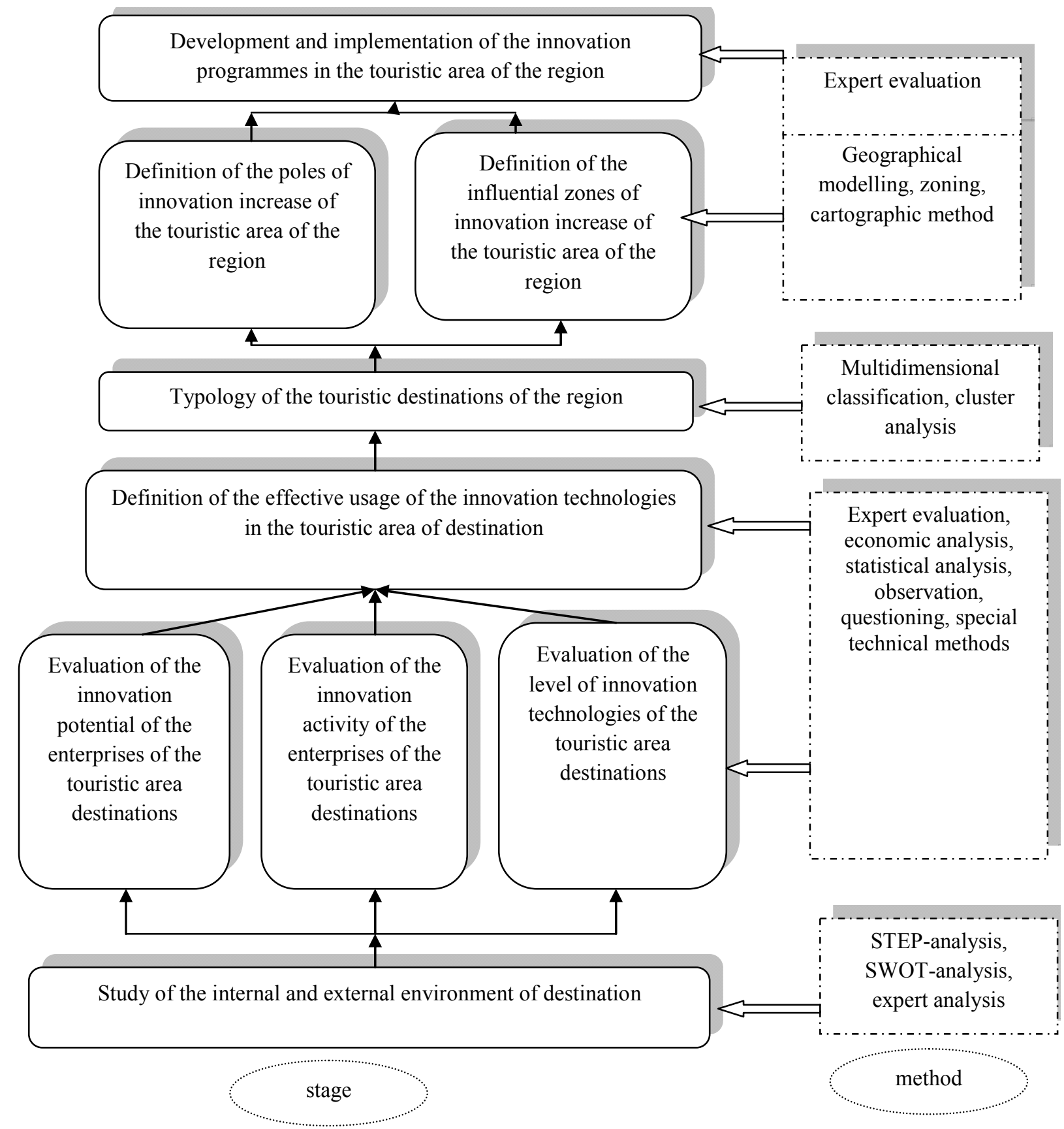

Figure 2. The methods of study of the innovation technologies in the tourism area (developed by the author) 


\section{Conclusion}

Offered implementation of the standardized structure will allow a tourist destination not only in Ukraine adequately represent its own tourist product through innovative technologies, but also enhance its competitiveness, and dissemination of information about it will be a platform for civil society initiatives in the tourism sector.

Reservation systems of integration to the basic services and social networks as Facebook, and Twitter, the availability of the special content for travelling - the search, routings, announcements holidays; multilingualism - duplication of the main pages in the two required languages - Ukrainian and English ones, as well as the languages of the target segments of the destination; enabling customers to pay for the certain goods and services directly on the site, and other.

All of this will help to increase the number of foreign tourists in Ukraine, and the dissemination of information about Ukraine and its destination at the international market.

\section{References}

Ali, A., \& Frew, A. J. (2011). ICT and Sustainable Tourism. UK: Queen Margaret University. Retrieved from http://www.academia.edu/180753/ICT_and_Sustainable_Tourism_-_Literature

Altunin, A. (2014). The electronic "word of mouth radio" in the industry of hospitality and tourism. RISK: Resources, information, provision, and competition, 2, 36-39.

Bezdudnyi, F. F., Smirnov, G. A., \& Nechaeva, O. D. (1998). The Essence of the Notion of Innovation and its Slassification. Innovations, 2-3, 3-13.

Bogdanova, A. L. (2012). The usage of electronic learning and teaching complex on the example of the discipline "Internet-technologies in tourism". Alma mater (The Digest of Higher School), 5, 98-100.

Ferreira, J., \& Estevao, C. (2014). Regional Competitiveness of Tourism Cluster: A Conceptual Model Proposal. Retrieved from http://mpra.ub.uni-muenchen.de/14853/1/MPRA_paper_14853.pdfpdf

Figueiredo, P., Gomes, S., \& Farias, R. (2010). Innovative technological capability in firms of the tourism sector: a study of the hotels in the city of Rio de Janeiro during the 1990-2008 period. Retrieved from http://www.scielo.br/pdf/rap/v44n5/v44n5a07.pdf

Gelman, V. Y. (2013). Internet-technologies in the amateur tourism. The Digest of the National Academy of Tourism, 2, 15-19.

Global Swot analysis. (2014). A report produced for TOUREG Project, Deliverable D.2.1 by the Department of Tourism Management of the Alexander Technological Educational Institute of Thessaloniki, Greece and the Technical University of Crete, Greece. Retrieved from http://www.stepc.gr/_docs/library_docs/GLOBAL_SWOT_Analysis_TOUREG.pdf

Golovko, O. M. (2012). Organization of the Hotel Economy. Kiev: Kondor. Retrieved from http://pidruchniki.ws/18831119/turizm/sutnist_tehnologichnih_protsesiv_tsikliv

Golubchenko, I. (2012). Innovations and geography. Innovations and geography, 1(2), 1-33.

Hjalager, A. M. (2002). Repairing Innovation Defectiveness in Tourism. Tourism Management, 23, 465-474. http://dx.doi.org/10.1016/S0261-5177(02)00013-4

Keller, P., \& Bieger, T. (2005). Innovation in Tourism-Creating Customer. Innovation and Product Development, $47,384$.

Kudasheva, L. O. (2012). The influence of the electronic commerce and Internet-resources on the development of the industry of the tourism. Transformation of the scientific paradigm and communicative practice in the information society, 2, 94-96.

Kuznetsov, G. S., Romanov A. A., \& Tultaev T. A. (2014). The virtual tourism as the contemporary form of activity on the touristic market. The Digest of the Scientific Works Sworld, 2(26), 28-35.

Lemesko, T. B. (2013). Internet-opportunities of promotion of the touristic services. The Achievements of the Pre-higher Science, 7, 314-318.

Maksimova, L. M. (2011). The usage of the instruments of Internet-monitoring for activation of the process of development of the entrance tourism in RF // The Contemporary Problems of Services and Tourism, 3, $43-48$. 
Malysheva, E. V. (2013). Internet as a means of formation of culture of consumption in the touristic industry: generation aspect. The Digest of Economy, Law and Sociology, 3, 219-222.

Melnichenko, C. (2007). Impact of Information Technology on the marketing of tourism enterprises. Herald KNTEU, 5, 10-21.

Pogorelov, A. M. (2014). The influence of the information technologies on the development of the international tourism. The Proceedings of the State University. Economic and Legal Sciences, 1-1, 122-127.

Portyanskii, I. A. (2012). Computer Arsenal of Geography. Moscow: Mysl.

Semenovich, V. S., \& Rodygin, L. A. (2007). Internet-technologies and commerce in the tourism: Tendencies and prognoses. The Digest of Moscow State Regional University. Series: Economy, 2, 101-105.

Serdyukova, N. K., \& Gavrilets G. Y. (2012). The evaluation of the contemporary tendencies of promotion of the touristic product. The Proceeding of Sochi State University, 3, 90-95.

Shvets, I. Y. (2013). The Methodological Problems of Research and Regional Management of the Competitive Ability of the Tourist Services. Kiev: VGL Obrii.

Skopen, N. N. (2005). Computers information technologies in tourism. Kiev: Condor.

Suvorova, I. N. (2012). Internet-intelligence and automated monitoring of sites of competitors in the area of the business tourismof RF. The Scientific Works of the Free Economic Association of Russia, 164, 250-255.

Turlapov, V. E. (2007). Geoinformative Systems in Economy. Nizhnij Novgorod: NF GU-VShE.

Umavova, B. T., \& Nazhmutdinova S. A. (2012). The usage of the Internet-technologies in marketing and tourism. The issues of structuring of economy, 1, 90-92.

\section{Copyrights}

Copyright for this article is retained by the author(s), with first publication rights granted to the journal.

This is an open-access article distributed under the terms and conditions of the Creative Commons Attribution license (http://creativecommons.org/licenses/by/3.0/). 